\title{
Brains versus beauty in the knowledge economy
}

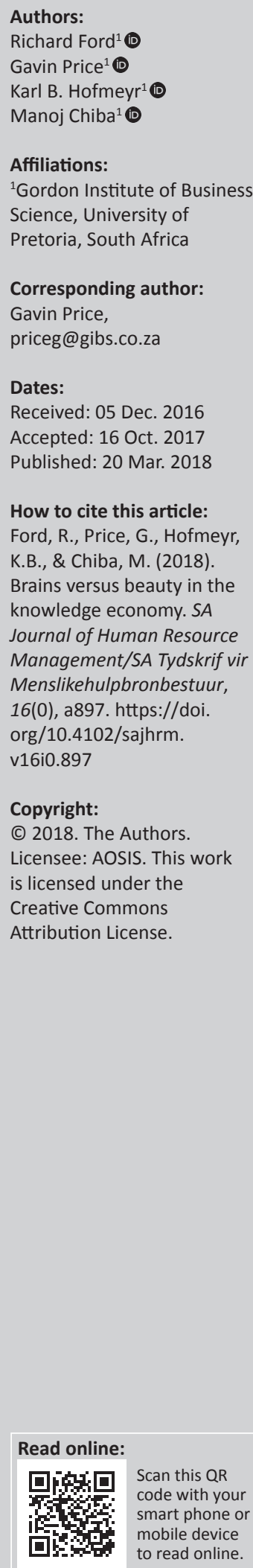

Orientation: It is a widely held belief that attractive people generally experience an easier life and that the door to success is opened by perfect bone structure and a sparkling smile. However, attractiveness might play a far lesser role in individual's achieving their objectives than has previously been thought. Is it possible that an individual's qualifications may have a greater influence on the perceptions of managers who assess the suitability of a candidate of a knowledge worker?

Research purpose: The study sets out to examine the relative predictive power of physical attractiveness and qualifications in the decision to hire a knowledge worker.

Motivation for the study: The research was motivated by a desire to explore the presence of bias in the decision-making process when seemingly rational individuals are exposed to factors such as physical attractiveness of a job candidate and then faced with a decision on whether to hire them.

Research design, approach and method: A two-phased experimental design was applied to investigate the existence and strength of the beauty premium amongst a group of managers who were provided with fictitious resumes coupled with photographs of the applicants. These managers were requested to make a hiring decision based on the information supplied.

Main findings: Although results confirm the existence of a beauty premium, it was relatively weak. It indicated that qualifications have a greater influence on a manager's perception of the suitability of a candidate to fill a position of a knowledge worker.

Practical or managerial implications: The research draws attention to the possibility of bias in selection decisions and proposes ways in which such potential bias can be limited.

Contribution: This study contributes to knowledge concerning the existence or otherwise of a so-called beauty premium, with particular reference to its impact in the knowledge economy.

\section{Introduction}

Recruitment decisions can detrimentally affect the performance of organisations if they are not objective and take factors other than the candidate's competence and potential into account. Aharon et al. (2001), Ariely (2008) and Caplan (2000) proposed that, under certain circumstances, humans can be biased and irrational in their decision-making process. With relevance to this study, there is research that suggests that the physical attractiveness of a person has a powerful influence on the decisions made by third-party decision-makers (Fletcher, 2009; Mobius \& Rosenblat, 2006). Simultaneously, there is much work that emphasises the need to employ the most capable person for the job based on objective criteria (DeGroot \& Gooty, 2009; Yamamura \& Birk, 2010).

Bias, as described by Rudolph, Wells, Weller and Baltes (2009), is a significant difference between the evaluations of two target individuals who, when everything is considered to be equal, vary only by some stigmatised quality or characteristic extraneous to their qualifications or job performance. This bias occurs in many forms, most notably when there are differences in gender (Arvey, 1979; Davison \& Burke, 2000; Deaux \& Taynor, 1973), race (Greenhaus, Parasuraman \& Wormley, 1990; Landau, 1995; Landy \& Farr, 1980; Schmidt \& Lappin, 1980) and weight (Puhl \& Brownell, 2001; Roehling, 1999, 2002).

\section{Purpose}

According to Sutherland and Jordaan (2004), recruitment and selection are some of the most critical human resource decisions an organisation can make. Specifically, in the knowledge economy, knowledge should be viewed as a major contributing factor to an organisation's success 
and the holders of this knowledge should therefore be focused on and viewed more favourably.

Similarly, industrial psychologists and management researchers have emphasised the need to detect and eliminate biases in personnel selection and recruitment (Watkins \& Johnston, 2000). This research was motivated by a desire to investigate the presence of bias in the decision-making process when seemingly rational individuals are exposed to factors such as the physical attractiveness of a job candidate and then faced with a decision on whether to hire them or to hire a less attractive individual who might have better or more suitable qualifications for the available position. In a competitive environment, there is a distinct need to employ a candidate who will help to maximise the output of the company. This research would examine the presence of bias in the hiring decisions of managers in a South African context, to make recruiters aware of this potential weakness and to assist them to optimise their employment decisions.

What is the effect of the physical attractiveness of an applicant on the initial hiring process before he or she is invited to be interviewed? Answers to this question would provide insight as to whether the attractiveness of a candidate plays a beneficial role in the hiring decision of managers when they are provided with a resume showing the applicant's face together with an explanation of the applicant's qualifications. This study sets out to assess whether the managers are more likely to hire a less qualified but more attractive applicant over a more qualified but less attractive applicant.

This research will contribute to the field of behavioural economics (Tomer, 2007), in particular decision-making bias in the context of the so-called beauty premium. Behavioural economics concerns itself with the prediction, controlling and experimental analysis of human behaviour, and one of its propositions is that systematic biases are built into the individual's selection processes and that these choices prevent utility maximisation (Etzioni, 2011).

\section{Literature review}

The potential decision-making bias in the labour market, where those perceived as being beautiful are more likely to be hired, earn higher salaries and are more likely to be promoted, suggests the existence of a 'beauty premium' (Solnick \& Schweitzer, 1999). What are the effects of the beauty premium on the perception of the physical attractiveness of others, and could there be discrimination based on this in the labour market?

Studies concerning bias, based on physical appearance in the labour market, are not new. However, most of these investigations have analysed beauty as a motivation for remuneration (Andreoni \& Petrie, 2008; Benzeval, Green \& Macintyre, 2013; French, 2002; Hamermesh \& Biddle, 1993; Mobius \& Rosenblat, 2006; Robins, Homer \& French, 2011; Tews, Stafford \& Zhu, 2009). This research would focus on hiring decisions. Although there are fewer studies of this nature, there has been research, for example, that concluded that physical attractiveness may not be viewed as positively as expected, particularly where unattractive females were rated to be more suitable than attractive women for male stereotyped industries (Dion \& Stein, 1978; Heilman, 1983; Heilman \& Saruwatari, 1979).

The context for this study was the knowledge economy. Although attractiveness might be more relevant in service jobs involving interpersonal interaction, Watkins and Johnston (2000) argued that attractiveness should be irrelevant in most instances concerning employment. It is proposed that this should be the case particularly for a knowledge worker in a knowledge economy.

\section{Beauty and the beauty premium}

Beauty is measured on the basis of physical attractiveness, perceptions of which have been confirmed in experiments. For example, experiments in which respondents ranging in age from 7 to 50 years were asked to rank the physical attractiveness of people in photographs demonstrated a very high correlation in their rankings (Hamermesh \& Biddle, 1993). Numerous studies have explored the existence of a beauty premium. For example, Cash, Gillen and Burns (1977) found that physical attractiveness affects personnel decisions to the general advantage of good-looking applicants, unless these perceived attractive people seek jobs considered inappropriate for their sex. Jin, Fan, Dai and Ma (2017) found the beauty premium present in online peer-to-peer lending, with lenders tending to be more tolerant towards attractive borrowers' dishonest behaviour. Similarly, Ma, Qian, $\mathrm{Hu}$ and Wang (2017) demonstrated that attractive male proposers playing the ultimatum game benefit from favourable bias because of their attractiveness, as a result of compromises to the fairness considerations of the female responders.

Research has suggested that good-looking candidates are hired because of the belief that they are more successful (Goldman \& Lewis, 1976), more credible (Patzer, 1983) and more able (Mobius \& Rosenblat, 2006) than their less attractive competition. Goldman and Lewis (1976) hypothesised that this could be because of attractive individuals displaying relatively higher levels of social skilfulness, thus resulting in a 'kernel of truth' in the above beliefs. According to the 'kernel of truth' hypothesis, the stereotype surrounding physical attractiveness might well be a self-fulfilling prophecy because better looking children are expected to outperform their peers and are thus given special treatment at school, which in turn builds confidence as well as social and communication skills (Mobius \& Rosenblat, 2006). These increased social and communication skills also help attractive individuals come across as being more credible (Patzer, 1983).

Hamermesh and Biddle (1993) analysed attractiveness across various occupations and found that, holding constant for demographic and labour-market characteristics, plain people 
earn less than people of average looks, who earn less than good-looking people. More recently, Fletcher (2009) found that attractiveness is positively associated with earnings for young adults, even when controlling for ability measures. Robins et al. (2011) concluded from their research that physical attractiveness affected wage determination, largely confirming earlier empirical and theoretical studies.

Patzer (1983), in his study of source credibility as a function of communicator physical attractiveness, summarised existing physical attractiveness research into four generalisations. When the physically attractive are compared with unattractive counterparts: they have greater social power, they are perceived to have more favourable personal and non-personal characteristics (including intelligence, personality traits and success in life), they have more positive effects on other people, they receive more positive responses from others and they are more persuasive. Patzer (1983) concluded that the consequences of being physically attractive are positive and the consequences of being physically unattractive are negative. These findings were supported by further evidence obtained in a study by Fletcher (2009) who, in his study entitled 'Beauty vs. brains, Early labour market outcomes of high school graduates', found that attractive and very attractive individuals earned between $5 \%$ and $10 \%$ more than average-looking individuals. Also, the study found that for very attractive individuals, an increase in ability was associated with an increase in wages; however, for individuals that were below average in attractiveness, the returns on ability could be negative, resulting in a 'plainness penalty'.

Although the studies above add to the evidence of a beauty premium, these investigations do not consider other variables which may be related to success in the work place. Robins et al. (2011) found that most studies do not take personality attractiveness and grooming into account (Ritts, Patterson \& Tubbs, 1992) and this may lead to research limitations. These authors found that when only beauty is measured it resulted in a beauty premium of approximately $12 \%$ for very physically attractive men, $7 \%$ for very physically attractive women and $4 \%$ for physically attractive women and men. When both personality attractiveness and grooming were added to their model, the beauty premium for men was slightly reduced but became statistically insignificant for women. Robins et al. (2011) concluded that while beauty is the most important of the three traits tested for men, it is the least important for women after personality attractiveness and grooming. This finding is significant because it emphasises the ability for women to minimise the effects of the beauty premium by controlling their demeanour and adjusting the way that they groom themselves.

In an experiment exploring beauty, gender and stereotypes, Andreoni and Petrie (2008) found that a beauty premium exists, but that this was only evident when total output was measured and groups performed tasks without knowing how much each member of the group had contributed. As soon as individual contributions were made known, the beauty premium disappeared. This finding suggested that people expect attractive individuals to be more cooperative but that when expectations are not met they may be less cooperative with attractive individuals. These findings confirmed the findings of Langlois, Kalakanis, Rubenstein and Larson (2000) that attractive people are consistently judged and treated more positively.

To establish the effects of a beauty premium, Solnick and Schweitzer (1999) investigated the role of physical attractiveness and gender in an experimental setting using a variation of Roth's (1995) ultimatum game. The aim of Solnick and Schweitzer's research was to explore the influence of physical attractiveness and gender on bargaining behaviour. Although they found that there were no significant differences in the decisions made by attractive and unattractive people, they concluded that, consistent with the notion of a beauty premium, significant differences arose in the way attractive individuals were treated by other players. Attractive people were offered more but more was demanded from them, whereas less was demanded from unattractive people.

Consistent with these findings, Hatfield (1986) found that the physical attractiveness stereotype can become a selffulfilling prophecy. He found that attractive children were often identified early on by teachers who expected them to outperform at school and these children were given special attention. This extra attention builds self-confidence as well as social and communication skills, which help the children later in life. This self-confidence has been confirmed in experiments where college students were asked to interact anonymously with each other via telephone and then judge, based on a 5-minute telephonic conversation, whether the person on the other end of the line was physically attractive or not (Goldman \& Lewis, 1976). The findings of the study found that there was a correlation between physical attractiveness and social and communication skills and thus, there was a 'kernel of truth' in the physically attractive stereotype. As such, it is often perceived that physically attractive people may be more capable, well adjusted and socially skilful than unattractive people.

The beauty premium is evidenced by recruiters who claimed that candidates' physical appearance significantly accounted for their assessment of the candidates 'fit' in an organisation (Solnick \& Schweitzer, 1999). Managers may use physical attractiveness to make generalised inferences about a candidate regarding employment suitability as it is an easily identifiable characteristic (Tews et al., 2009). In a related study, $50 \%$ of employers who had recently hired candidates to fill a position answered that physical appearance was very important $(11 \%)$ or somewhat important (39\%) (Holzer, 1993). In Tews et al.'s (2009) study on organisational fit, the authors found that once applicants had been screened and were deemed to meet the minimum requirement for the job, qualification was no longer important. The assessment of fit, which included interpersonal skills, goal orientation and physical 
attractiveness, involved something beyond the evaluation of knowledge, skills, abilities and past accomplishments.

Rynes and Bourdreau (1986) have suggested that very little time is spent on training interviewers on how to evaluate applicants' suitability and this may lead to bias that is based on physical appearance or the 'what is beautiful is good' stereotype (Patzer, 1983).

Tews et al. (2009) found that when positive attributes are ascribed to the physically attractive, this may lead to a positive effect on hiring decisions, but when details of the applicants' general mental ability (GMA) and personality were recorded, the results demonstrated that attractiveness was valued less than both of these attributes. This finding concluded that managers do try to make hiring decisions based on employee ability to maximise job performance. However, if managers are not provided with the right information, hiring decisions may be made on the basis of physical attractiveness of the candidate, and as such, these candidates could be 'beating' the selection system (Tews et al., 2009). In summary, the attractiveness advantage has been demonstrated in workrelated settings, and although high-performing candidates are preferred in comparison to low-performing candidates, regardless of their level of attractiveness, research has found that in general attractive people are favoured over equally qualified unattractive people in hiring decisions (Dipboye, Arvey \& Terpstra, 1977; Dipboye, Fromkin \& Wibak, 1975; Raza \& Carpenter, 1987). Deryugina and Shurchkov (2015) found that a beauty premium, in the form of higher wage bids, existed in tasks involving bargaining, but not ones involving analytics or data entry.

\section{Bias in selection}

Despite legislation that attempts to decrease the level of discrimination by employers on factors unrelated to job performance, studies have shown that discrimination based on external factors unrelated to job performance, such as age and sex, still exist (Gerdes \& Garber, 1983). These biases can be further compounded by the differences amongst the raters of job applicants (Quereshi \& Kay, 1986). Demographical characteristics of the rater, such as age, sex, years of experience and sensitivity to discrimination issues, seem to affect the degree of bias displayed in hiring practices (Martinko \& Gardner, 1983; Quereshi, 1983; Quereshi, Buckley \& Fadden, 1981).

Dipboye et al. (1977) found in their research that regardless of the sex or attractiveness of the interviewer, highly qualified applicants were preferred over poorly qualified applicants, male applicants were preferred over female applicants and attractive applicants were preferred over unattractive applicants. The research concluded that discrimination in employment decisions can be attributed to sex-role and physical attractiveness stereotypes.

The research of Marlowe, Scheider and Nelson (1996) suggests that biases may decrease as an individual's exposure to the qualifications and performance of others increases (Marlowe et al., 1996). This may be a result of experienced managers having a wider range of performance on which to base their judgements, and as a result, they may be less susceptible to bias, based on the attractiveness of an applicant.

Limited research has been conducted that explores the existence of bias in the earlier phases of the personnel selection process; for example, the screening of applicants prior to the job interview (Dipboye et al., 1975). In many cases, the screening and interviews are performed by the same person, and negative first impressions and psychological or actual rejection of the candidate may take place before the actual interview process has commenced. Dipboye et al. (1975) found that scholastic standing was the most important determinant of suitability ratings and rankings, accounting for more than $30 \%$ of the variance. When applicants had equivalent scholastic standing, subjects revealed a strong preference for males and attractive applicants. This outcome indicates that, assuming scholastic standing is the most rational basis for discriminating between applicants, persons with equivalent qualifications had unequal probabilities of being hired (Dipboye et al., 1975).

The researchers also found that the subjects discriminated more against unattractive applicants and females when deciding which candidate would be assigned the top rank. This is significant because in a recruitment situation where applicants far outnumber positions available, it is critical for an applicant to be ranked amongst the highest candidates in order to be hired or invited for an interview. It is also important to note the effect that the sex or the attractiveness of the applicant may have on the interviewer's behaviour subsequent to them evaluating the applicant's resume. Research by Mayfield (1964) demonstrated that interviewers tend to form an early impression. Thus, the ability of the applicant to convey gender and attractiveness to the interviewer through resume information may assist in creating an initial impression, which influences the outcome of the face-to-face interview (Dipboye et al., 1975).

Watkins and Johnston (2000) found that applicant attractiveness had no impact when the quality of the application was high, but that attractiveness was an advantage when the quality of the application was mediocre. As physical attractiveness is unrelated to job performance in most cases, any bias towards physically attractive applicants represents discrimination (Watkins \& Johnston, 2000). Huang and Lin (2016) found that physically attractive males receive favourable interview questions and have higher levels of self-confidence, resulting in better interview performance compared to other males.

Put simply, Cash and Janda (1984) proposed that when meeting someone for the first time for a job interview, the characteristic that carries the most weight in making a good impression is physical appearance. Individuals form first impressions of others on the basis of their immediately 
apparent features, most notably physical appearance (McArthur \& Baron, 1980). The results of studies using fictitious resumes and applicants of varying attractiveness clearly reveal the potential for discrimination in hiring based on physical attractiveness (Cash et al., 1977; Cash \& Kilcullen, 1985; Dipboye et al., 1975, 1977; Holahan \& Stephan, 1981).

Maurer-Fazio and Lei (2015) found the beauty premium to be present across both males and females in the hiring process. Ruffle and Shtudiner (2015), however, found that only attractive males benefited. They found that attractive females were prejudiced, postulating that such prejudice was envy based.

\section{The knowledge economy and knowledge workers}

The term 'knowledge economy' is a broad term (Powell \& Snellman, 2004) without a clear definition. Rather, it is widely used as a metaphor (Smith, 2002). For the purpose of this study, the knowledge economy is defined as:

... production and service based on knowledge-intensive activities that contribute to an accepted pace of technical and scientific advance, as well as rapid obsolescence ... the key component of which is the greater reliance on intellectual capability than on physical inputs and natural resources. (Powell \& Snellman, 2004:99)

This definition reflects the transition that has occurred in advanced industrialised nations from manufacturing-based to service-driven economies.

A feature of the knowledge economy is the increase in the mobility of knowledge workers which leads to higher levels of recruitment and selection (Sutherland \& Wöcke, 2011). Recruitment and selection is the process of making fair and relevant assessments of the strengths and weaknesses of applicants with the intent to hire them (Boxall \& Purcell, 2008). This definition of recruitment is the basis upon which this study was conducted. The research would explore the notion that knowledge should be the most important factor in the knowledge economy and that it is a scarce resource. Hiring of knowledge workers should be as objective as possible without regard for factors such as the attractiveness of candidates.

This study sets out to fill an existing gap in the literature and determines the prevalence of bias towards attractive individuals during the hiring practices of knowledge workers. Although a beauty premium is, according to the literature, expected in cases where other factors are equal, the context of the knowledge economy should dictate that potential employers will favour the more technically competent applicants, and thus, there should be no employerbias based on the physical appearance of the job applicant. The following two-part research question was thus posed:

- Do both physical attractiveness and qualifications of an applicant for the position of a knowledge worker influence a manager's perception of the suitability of such applicant? And if so, which of the two factors is more influential?

The hypotheses used to answer the research questions were as follows:

- Hypothesis $1\left(\mathrm{H}_{1 \mathrm{~A}}\right)$ : Both qualifications and attractiveness influence a manager's perceived suitability of an applicant to fill the position of a knowledge worker.

- Hypothesis $2\left(\mathrm{H}_{2 \mathrm{~A}}\right)$ : Qualifications are more influential than attractiveness in a manager's perception of an applicant's suitability to fill the position of a knowledge worker.

\section{Method Research design}

The researchers used a descriptive, cross-sectional and quantitative research to collect primary data to answer the hypotheses. This approach enabled the researchers to understand if being attractive and/or qualified had any effect on the hiring decisions of managers. The design thus allowed for the measurement of the effect of the two independent variables of attractiveness and qualifications on the dependent variable, namely, the suitability of the candidate for the position as a knowledge worker.

The research took place as a two-phase quantitative study. The first phase was designed to obtain a rank order of the attractiveness of a set of applicants to be used in phase two, which, in turn, was designed to simulate the practice of screening applicants' resumes prior to a job interview.

\section{Sampling}

A non-probability convenience sample was used for this study to maximise the number of responses within the time and financial constraints of the study (Saunders, Lewis \& Thornihill, 2012). The research was conducted in two phases. For phase 1, the questionnaire was distributed to $N=10$ Executive Master of Business Administration (EMBA) students at the Gordon Institute of Business Science, and all $N=10$ respondents returned the questionnaire, with no missing data or errors, representing a $100 \%$ response rate. For phase 2, $N=115$ questionnaires were distributed to Programme in Management Development (PMD) students at the same institution, with $N=113$ questionnaires returned with 10 containing errors and subsequently not included in the final analysis; therefore, the final analysis $N=103$, representing an $89.56 \%$ complete response rate. The respondents represented a variety of management experience. Of the respondents, $43.69 \%(n=45)$ had between 5 and 9 years of management experience, with $39.81 \%(n=41)$ having $0-4$ years' management experience, whereas $16.54 \%$ ( $n=17)$ of respondents having 10 or more years of experience. As managers are predominantly responsible for making hiring decisions, these respondents were deemed suitable for the study. 


\section{Measuring instruments}

The research was conducted in two phases. Questionnaires were used in both phases of the research, using a selfreporting ranking scale.

\section{Phase 1}

Phase 1 was conducted primarily to establish a collection of photographs that respondents in phase 2 would deem attractive and not attractive. A questionnaire containing two sections was used. Section 1 allowed for the collection of demographic information, namely age, gender, race and occupation of respondents. Section 2 contained a set of 16 head and shoulder photographs of 8 Caucasian males and 8 Caucasian females. The researchers used a single race group to control for racial preference, which simultaneously allowed for the controlling of extraneous variables of height, speech, confidence levels and body language (Patzer, 1983).

The respondents were presented with the photographs and asked to rank each gender on a scale from 1 (least attractive) to 8 (most attractive). The two least attractive and the two most attractive photographs for each gender were then used in phase 2 of the research.

\section{Phase 2}

Phase 2 was conducted to test the hypotheses, based on the results of phase 1 of attractive and not attractive candidates. The questionnaire used in phase 2 contained four sections. Section 1 allowed for the collection of demographic information, namely age, gender, race, occupation and amount of management experience. Management experience was measured through self-reported number of years at specific management levels such as general management and executive management. Section 2 contained a fictitious knowledge worker job description and Section 3 contained eight CVs, each with one of the eight photographs comprising of two attractive males, two attractive females, two nonattractive males and two non-attractive females, as assessed in phase 1. Lastly, Section 4 contained a matrix and instructions for the respondents to rank the suitability of the eight candidates for the knowledge worker position.

All CVs met the minimum criteria for fulfilling the role; however, four of the CVs contained information depicting the candidate to be patently more qualified than the minimum requirements for the advertised position. Each $\mathrm{CV}$ was standardised in format, all photographs were in colour on the top left of the page, accompanied by the name and surname of the fictitious candidates, location and date of birth, career objectives, educational qualifications, experience, language spoken and hobbies.

The different levels of attractiveness (attractive and not attractive) and combinations of resume (highly qualified and minimally unqualified) were manipulated according to the design matrix illustrated in Table 1. For attractiveness, +1 represents attractive as ranked in phase 1 , whereas -1
TABLE 1: Summary of knowledge worker job application scenarios.

\begin{tabular}{lccl}
\hline Scenario & Attractive & Qualification & Gender \\
\hline 1 & +1 & +1 & Male \\
2 & -1 & +1 & Male \\
3 & +1 & -1 & Male \\
4 & -1 & -1 & Male \\
5 & +1 & +1 & Female \\
6 & -1 & +1 & Female \\
7 & +1 & -1 & Female \\
8 & -1 & -1 & Female \\
\hline
\end{tabular}

represents unattractive as ranked in phase 1. For qualification, +1 represents highly qualified, whereas -1 represents minimally qualified.

Eight scenarios as summarised in Table 1 were used as stimuli to determine if physical attractiveness and qualifications influence suitability of applicants for a knowledge worker related job specification. The format of a resume was chosen to improve the external validity as these represent real-life situations of how candidates are assessed for suitability for job roles. The resumes were further designed, as outlined above, so as not to include any additional information that could influence the attractiveness of the resume for some respondents.

Prior to distribution of the questionnaires, pretesting was conducted to ensure that participants understood the job specification and the accompanying resume with photographs. This was conducted with a further 10 EMBA students, and all respondents agreed that the fictitious job description, resumes and instructions were clear and no changes were required.

The researchers distributed the four sections of the questionnaire in unmarked A4 white envelopes. A random number generator to determine the order that the resumes were placed in each envelope before being handed out. The researchers also verbally repeated the instructions contained in the envelopes to the respondents before the envelopes were handed out. The data collection was conducted in the same setting for all respondents to provide uniform conditions.

\section{Data analysis}

To test the research hypotheses, the second phase of the research was conducted to establish the presence of any bias based on the beauty premium. The results of the survey were transcribed into an Excel spread sheet and the subjects were each given an identification number from 1 to 103 .

These details were then recorded into SPSS version 22, where multiple Wilcoxon signed rank tests were performed that compared the following variables and their effects and influence on:

- attractive versus unattractive

- qualified versus unqualified

- attractive qualified versus attractive unqualified

- unattractive qualified versus unattractive unqualified 
- unattractive qualified versus attractive unqualified

- unattractive unqualified versus attractive unqualified

- attractive qualified versus unattractive qualified.

\section{Results}

\section{Sample characteristics}

One hundred and thirteen responses were received, with 103 participants that were used in the final analysis. The sample characteristics are summarised in Table 2. From these characteristics, it may be concluded that the sample is reasonably typical of South African middle managers.

\section{Candidates}

Based on the photographs and resumes, respondents ranked the fictitious candidates and the results are reflected in Table 3.

Table 3 expresses the frequency of each candidate's rankings. For example, the male attractive qualified candidate received a ranking of six 23 times. It is interesting to note that both male and female qualified candidates scored consistently higher in the rankings than their unqualified counterparts. This will be discussed in more detail in the results section.

Table 4 presents the rankings for the candidates by considering whether they were attractive or unattractive or qualified or unqualified, regardless of their gender. The results presented are interesting because they show a fairly even distribution of ranking for the attractive and unattractive applicants, whereas the results for qualified and unqualified applicants are unsurprisingly in favour of qualified applicants.

Owing to the data being prepared in rank order, a Wilcoxon signed rank test was applied. When analysing

TABLE 2: Sample characteristics.

\begin{tabular}{|c|c|}
\hline Characteristics & $n$ \\
\hline \multicolumn{2}{|l|}{ Gender $^{a}$} \\
\hline Male & 51 \\
\hline Female & 51 \\
\hline \multicolumn{2}{|l|}{ Race group ${ }^{b}$} \\
\hline Black & 46 \\
\hline White & 34 \\
\hline Indian & 12 \\
\hline Mixed race & 8 \\
\hline \multicolumn{2}{|c|}{ Age group in years ${ }^{c}$} \\
\hline $25-29$ & 12 \\
\hline 30-34 & 33 \\
\hline 35-39 & 30 \\
\hline $40-44$ & 21 \\
\hline $45-49$ & 5 \\
\hline $50-54$ & 2 \\
\hline \multicolumn{2}{|c|}{ Management experience in years } \\
\hline$<4$ & 41 \\
\hline $5-9$ & 45 \\
\hline 10-14 & 11 \\
\hline$>15$ & 6 \\
\hline
\end{tabular}

the Wilcoxon signed rank test, the higher the mean rank, the more likely the choice (Pallant, 2010). Results are presented in Table 5.

The results from the ranks above demonstrate both the respondents' preference for an applicant and the strength of the preference. The following phenomena can be observed using the key above:

- Unattractive applicants were preferred to attractive applicants.

- Qualified applicants were preferred to unqualified applicants.

- Attractive qualified applicants were preferred to attractive unqualified applicants.

- Unattractive qualified applicants were preferred to unattractive unqualified applicants.

- Unattractive qualified applicants were preferred to attractive unqualified applicants.

- Attractive unqualified applicants were preferred to unattractive unqualified applicants.

- Attractive qualified applicants were preferred to unattractive qualified applicants.

The researchers also ran a test for effect size for each of the statistical hypotheses and used the guidance provided by Cohen (1988), namely that an $r$-value of $0.1=$ a small effect, $0.3=$ a medium effect and $0.5=$ a large effect.

As can be seen in Table 6, the Wilcoxon signed rank test revealed the following:

TABLE 3: Frequency of rank per candidate.

\begin{tabular}{lcccccccc}
\hline Rank & $\mathbf{1}$ & $\mathbf{2}$ & $\mathbf{3}$ & $\mathbf{4}$ & $\mathbf{5}$ & $\mathbf{6}$ & $\mathbf{7}$ & $\mathbf{8}$ \\
\hline Male attractive qualified & 6 & 12 & 8 & 16 & 15 & 23 & 11 & 12 \\
Male unattractive qualified & 6 & 10 & 6 & 12 & 14 & 11 & 23 & 21 \\
Female attractive qualified & 1 & 10 & 15 & 10 & 11 & 19 & 15 & 22 \\
Female unattractive qualified & 14 & 8 & 11 & 8 & 14 & 8 & 20 & 20 \\
Male attractive unqualified & 10 & 9 & 19 & 16 & 16 & 12 & 8 & 13 \\
Male unattractive unqualified & 7 & 20 & 18 & 16 & 18 & 13 & 8 & 3 \\
Female attractive unqualified & 39 & 14 & 8 & 7 & 8 & 10 & 10 & 7 \\
Female unattractive unqualified & 20 & 20 & 18 & 18 & 7 & 7 & 8 & 5 \\
\hline
\end{tabular}

TABLE 4: Cumulative totals for candidate ranking based on qualification and attractiveness.

\begin{tabular}{|c|c|c|c|c|c|c|c|c|c|}
\hline Row labels & 1 & 2 & 3 & 4 & 5 & 6 & 7 & 8 & $\begin{array}{c}\text { Grand } \\
\text { total }\end{array}$ \\
\hline \multicolumn{10}{|l|}{ Attractive } \\
\hline $\begin{array}{l}\text { Attractive } \\
\text { count }\end{array}$ & 56.00 & 45.00 & 50.00 & 49.00 & 50.00 & 64.00 & 44.00 & 54.00 & 412 \\
\hline Row \% & 13.59 & 10.92 & 12.14 & 11.89 & 12.14 & 15.53 & 10.68 & 13.11 & 100 \\
\hline \multicolumn{10}{|l|}{ Unattractive } \\
\hline $\begin{array}{l}\text { Unattractive } \\
\text { count }\end{array}$ & 47.00 & 58.00 & 53.00 & 54.00 & 53.00 & 39.00 & 59.00 & 49.00 & 412 \\
\hline Row \% & 11.41 & 14.08 & 12.86 & 13.11 & 12.86 & 9.47 & 14.32 & 11.89 & 100 \\
\hline \multicolumn{10}{|l|}{ Qualified } \\
\hline $\begin{array}{l}\text { Qualified } \\
\text { count }\end{array}$ & 27.00 & 40.00 & 40.00 & 46.00 & 54.00 & 61.00 & 69.00 & 75.00 & 412 \\
\hline Row \% & 6.55 & 9.71 & 9.71 & 11.17 & 13.11 & 14.81 & 16.75 & 18.20 & 100 \\
\hline \multicolumn{10}{|l|}{ Unqualified } \\
\hline $\begin{array}{l}\text { Unqualified } \\
\text { count }\end{array}$ & 76.00 & 63.00 & 63.00 & 57.00 & 49.00 & 42.00 & 34.00 & 28.00 & 412 \\
\hline Row \% & 18.45 & 15.29 & 15.29 & 13.83 & 11.89 & 10.19 & 8.25 & 6.80 & 100 \\
\hline
\end{tabular}


TABLE 5: Wilcoxon signed rank test results.

\begin{tabular}{|c|c|c|c|c|}
\hline Row labels & Ranks & $N$ & Mean rank & Sum of ranks \\
\hline \multirow{4}{*}{$\begin{array}{l}\text { Unattractive- } \\
\text { attractive }\end{array}$} & Negative ranks & $214^{\mathrm{a}}$ & 201.70 & 43164.00 \\
\hline & Positive ranks & $198^{b}$ & 211.69 & 41914.00 \\
\hline & Ties & $0^{c}$ & - & - \\
\hline & Total & 412 & - & - \\
\hline \multirow{4}{*}{$\begin{array}{l}\text { Unqualified- } \\
\text { qualified }\end{array}$} & Negative ranks & $283^{d}$ & 212.56 & 60154.00 \\
\hline & Positive ranks & $129^{e}$ & 193.21 & 24924.00 \\
\hline & Ties & $0^{f}$ & - & - \\
\hline & Total & 412 & - & - \\
\hline \multirow{4}{*}{$\begin{array}{l}\text { Attractive } \\
\text { unqualified- } \\
\text { attractive } \\
\text { qualified }\end{array}$} & Negative ranks & $141^{\mathrm{g}}$ & 104.33 & 14711.00 \\
\hline & Positive ranks & $65^{h}$ & 101.69 & 6610.00 \\
\hline & Ties & $0^{i}$ & - & - \\
\hline & Total & 206 & - & - \\
\hline \multirow{4}{*}{$\begin{array}{l}\text { Unattractive } \\
\text { unqualified- } \\
\text { unattractive } \\
\text { qualified }\end{array}$} & Negative ranks & $142^{j}$ & 108.61 & 15422.50 \\
\hline & Positive ranks & $64^{k}$ & 92.16 & 5898.50 \\
\hline & Ties & $0^{1}$ & - & - \\
\hline & Total & 206 & - & - \\
\hline \multirow{4}{*}{$\begin{array}{l}\text { Unattractive } \\
\text { qualified- } \\
\text { attractive } \\
\text { unqualified }\end{array}$} & Negative ranks & $79^{m}$ & 87.76 & 6933.00 \\
\hline & Positive ranks & $127^{n}$ & 113.29 & 14388.00 \\
\hline & Ties & $0^{\circ}$ & - & - \\
\hline & Total & 206 & - & - \\
\hline \multirow{4}{*}{$\begin{array}{l}\text { Unattractive } \\
\text { unqualified- } \\
\text { attractive } \\
\text { unqualified }\end{array}$} & Negative ranks & $106^{p}$ & 105.80 & 11215.00 \\
\hline & Positive ranks & $100^{9}$ & 101.06 & 10106.00 \\
\hline & Ties & $0^{r}$ & - & - \\
\hline & Total & 206 & - & - \\
\hline \multirow{4}{*}{$\begin{array}{l}\text { Unattractive } \\
\text { qualified- } \\
\text { attractive } \\
\text { qualified }\end{array}$} & Negative ranks & $100^{\mathrm{s}}$ & 103.69 & 10368.50 \\
\hline & Positive ranks & $106^{t}$ & 103.33 & 10952.50 \\
\hline & Ties & $0^{u}$ & - & - \\
\hline & Total & 206 & - & - \\
\hline
\end{tabular}

a, Unattractive < attractive; ${ }^{\mathrm{b}}$, unattractive $>$ attractive; ${ }^{\mathrm{c}}$, unattractive = attractive; ${ }^{\mathrm{d}}$, unqualifie < qualified; ${ }^{\mathrm{e}}$, unqualified > qualified; ${ }^{\mathrm{f}}$, unqualified $=$ qualified; $\mathrm{s}$, attractive unqualified $<$ attractive qualified, $h$ attractive unqualified $>$ attractive qualified; 1 , attractive unqualified attractive qualified; ${ }^{\text {, }}$, attractive unqualified $>$ attractive qualified; ${ }^{\text {, attractive unqualified }}$ attractive qualified; , unattractive unqualified < unattractive qualified; k, unattractive unqualified $>$ unattractive qualified; , , unattractive unqualified = unattractive qualified; " unattractive quafied < attractive unqualified, , unattractive qualified > attractive unqualified; attractive unqualified, ', unattractive unqualified > attractive unqualified; ', unattractiv unqualified = attractive unqualified; ${ }^{\mathrm{s}}$, unattractive qualified $<$ attractive qualified; unattractive qualified $>$ attractive qualified; ${ }^{\prime}$, unattractive qualified $=$ attractive qualified.

TABLE 6: Test statistics.

\begin{tabular}{lcc}
\hline Combination of independent variables & $z$ & Asymptotic (two-tailed) \\
\hline Unattractive-attractive & $-0.259^{\mathrm{a}}$ & 0.795 \\
Unqualifed-qualified & $-7.310^{\mathrm{a}}$ & 0.000 \\
Attractive unqualified-attractive qualified & $-4.747^{\mathrm{a}}$ & 0.000 \\
Unattractive unqualified-unattractive qualified & $-5.581^{\mathrm{a}}$ & 0.000 \\
Unattractive qualified-attractive unqualified & $-4.364^{\mathrm{b}}$ & 0.000 \\
Unattractive unqualified-attractive unqualified & $-0.653^{\mathrm{a}}$ & 0.514 \\
Unattractive qualified-attractive qualified & $-0.343^{\mathrm{b}}$ & 0.732 \\
\hline
\end{tabular}

a, Based on positive ranks; ${ }^{\text {b }}$, based on negative ranks.

- A difference in ranks between qualified and unqualified applicants $(z=-7.310, p<0.05)$ based on their rankings by managers to fill the position of a knowledge worker, with a medium effect size of 0.3601 .

- A difference in ranks between attractive qualified and attractive unqualified applicants $(z=-4.747, p<0.05)$ based on their rankings by managers to fill the position of a knowledge worker, with a medium effect size of 0.3307 .

- A difference in ranks between unattractive qualified and unattractive unqualified applicants $(z=-5.581, p<0.05)$ based on their rankings by managers to fill the position of a knowledge worker, with a medium effect size of 0.3889 .

- A difference in ranks between unattractive qualified and attractive unqualified applicants $(z=-4.364, p<0.05)$ based on their rankings by managers to fill the position of a knowledge worker, with a medium effect size of 0.3040 .

The difference in ranks between attractive and unattractive applicants was not significant $(z=-0.259, p=0.759)$. Similarly, the difference in ranks between attractive unqualified and unattractive unqualified applicant was not significant $(z=-0.653, p=0.514)$, and furthermore, there was no difference in ranks between attractive qualified and unattractive qualified applicants $(z=-0.343, p=0.732)$ based on their ranking by managers to fill the position of a knowledge worker.

Thus, the findings of the study do not support Hypothesis 1 because only qualifications and not the attractiveness of the candidates were found to have a significant difference $(p<0.05)$ effect on the decision of the managers. However, the findings of the study support Hypothesis 2 .

\section{Discussion}

The research set out to answer the following question:

- Do both physical attractiveness and qualification of an applicant for the position of a knowledge worker influence a manager's perception of the suitability of such applicant? And if so, which of the two factors is more influential?

To do this, it was necessary to isolate the variables of qualification and attractiveness for these to be compared. The central finding from the research was that, in a context where qualifications are considered important, when a subject is provided with the details of a prospective applicant's qualifications, managers are more likely to make a hiring decision based on the applicant's qualifications rather than the applicant's physical appearance. This finding was contrary to some previous research (Dipboye et al., 1975).

The researchers attempted to recreate a realistic environment by sampling a diverse group of men and women with different racial backgrounds and management experience. The research made use of photographs of applicants for the job of a knowledge worker on the basis that past experiments had found that photographs demonstrated a very high correlation in the ranking on an individual's attractiveness (Hamermesh \& Biddle, 1993).

By considering Goldman and Lewis's (1976) postulation that attractive individuals display a higher level of social skilfulness, the researchers eliminated this variable by not having any personal interaction between the respondents and the applicants. Owing to this lack of personal interaction between the subject and the applicant, the variable of grooming was also eliminated apart from any grooming that was evident to the respondent from the photograph of the applicant.

Owing to the nature of the research experiments, the researchers were unable to confirm that good-looking 
candidates are hired in the belief that they are more successful (Goldman \& Lewis, 1976), more credible (Patzer, 1983) or more able (Mobius \& Rosenblat, 2006) than their less attractive competition, only that they were, in fact, preferred. The research aimed to analyse the effect of physical attractiveness on the initial hiring process before an applicant was invited for an interview. This means that applicant's social power, favourable personal and nonpersonal characteristics such as personality and success in life, positive effects on people and persuasive ability were not tested for as these factors would only be available for testing in an environment where there was personal interaction between the subjects and the applicants.

The results of this research demonstrated that the research subjects placed a higher value on qualifications than they did on physical attractiveness. In the case of one of the candidates (Female, Attractive, Unqualified), it appears she may have been negatively prejudiced for being perceived as being attractive and unqualified, thus supporting the findings of Maurer-Fazio and Lei (2015). The findings are also consistent with the research of Dion and Stein (1978), Heilman (1983) and Heilman and Saruwatari (1979) who concluded that attractiveness may not always be viewed positively.

The researchers found that, although qualification was the most important factor when selecting an applicant to fill the position of a knowledge worker, attractiveness of the applicant played a secondary role. This is consistent with Tews et al. (2009) who found that physical attractiveness had a positive effect on hiring decisions, but when details of the applicant's GMA were given, attractiveness as an attribute was less valued.

Research on organisational fit has suggested another reason that physically attractive applicants could be favoured over unattractive applicants (Tews et al., 2009). Once an applicant has been screened and deemed to meet the minimum requirements of the job being applied for, qualification was no longer deemed important. Tews et al. (2009) concluded that the assessment of fit involved something beyond the evaluation of knowledge, skills, abilities and past accomplishments but rather that interpersonal skills, goal orientation and physical attractiveness were considered important.

As the researchers in this study excluded details on the applicant's goal orientation and controlled for interpersonal skills, it is feasible that physical attractiveness, while not significant, was used as a secondary measure in order to select the applicant.

Although for this study the attractiveness of the research subject was not measured, the study found that, regardless of the sex of the research subject, they preferred qualified applicants to unqualified applicants, and when qualification was equal, the respondents preferred attractive over unattractive applicants. Thus, it can be concluded that there is discrimination in the employment decision that can be attributed to physical attractiveness stereotypes.

Because the researchers controlled for interview technique, grooming and social skill and only provided details on qualifications, past experience, hobbies and a photograph to display physical attractiveness, it is reasonable to determine that the hiring decision was made using primarily the applicant's qualifications and their physical attractiveness.

The study confirmed, similar to Dipboye et al. (1975), that qualifications were the most important determinants of suitability rating and ranking. However, their research found that when applicants had equal scholastic standing, subjects revealed a strong preference for attractive applicants, whereas this study revealed that subjects displayed only a non-significant preference for attractive applicants. The evidence found by the researchers confirms the findings of Watkins and Johnston (2000), who concluded that applicant attractiveness had no impact when the quality of the applicant was high but that it only played a role when applicant quality was mediocre. The researchers found that in the case of both qualified and unqualified applicants that attractiveness was preferred, even though it was only slightly so, over unattractiveness on a likefor-like basis, that is, attractive qualified applicants were preferred over unattractive qualified applicants, and attractive unqualified applicants were preferred over unattractive unqualified applicants.

\section{Conclusion}

The researchers can conclude that in the context of knowledge workers, a beauty premium does marginally exist but that it is less strong than might have been expected. Significantly more value is placed on the qualification of a job seeker than their physical attractiveness.

Congruent with research that has previously been conducted, the researchers found that regardless of the attractiveness of the applicant, more relevance is placed on the qualifications of the applicant in order to assess suitability to fill a position as a knowledge worker. However, when the quality of two applicants' qualifications is equivalent, the more attractive applicant is likely to be selected.

Unlike Watkins and Johnston (2000) who found that attractiveness can compensate for poor application quality, the researchers found that the attractiveness of an applicant would only help when high-quality applicants or low-quality applicants were competing for a position. The attractiveness of an applicant would not give them an advantage over a more highly skilled applicant.

In conclusion, like Cash et al. (1977), Cash and Kilcullen (1985), Dipboye et al. (1975), Dipboye et al. (1977) and Holahan and Stephan (1981), the researchers found that when subjects were presented with fictitious resumes depicting applicants of varying attractiveness, the results 
indicated that there is some potential for discrimination in hiring on the basis of physical attractiveness.

\section{Areas for further study}

During the course of conducting this research, the researchers identified numerous factors that might warrant further exploration, namely the existence of bias towards different types of qualifications of a knowledge worker, that is, CA versus B.Eng versus BCom versus BA and gender bias in the knowledge economy.

Further, the provision of proper training to the individuals in human resource (HR) and recruitment responsible for hiring decisions could be explored to ascertain whether adequate training diminishes the effect of the beauty premium amongst similarly qualified individuals.

The researchers were also unable to confirm that attractive candidates are hired in the belief that they are more successful (Goldman \& Lewis, 1976), more credible (Patzer, 1983) and more able (Mobius \& Rosenblat, 2006) than their less attractive competition, only that they were preferred. Further research could explore why attractive candidates are preferred, albeit marginally, in the context of knowledge workers.

\section{Acknowledgements Competing interests}

The authors declare that they have no financial or personal relationships that may have inappropriately influenced them in writing this article.

\section{Authors' contributions}

R.F. undertook the initial study while a student at the Gordon Institute of Business Science, University of Pretoria. G.P. supervised the research and was the lead author. K.B.H. and M.C. contributed to the writing of the article.

\section{References}

Aharon, I., Etcoff, N., Ariely, D., Chabris, C.F., O'Connor, E., \& Breiter, H.C. (2001) Beautiful faces have variable reward value, FMRI and behavioral evidence. Neuron, 32(3), 537-551. https://doi.org/10.1016/S0896-6273(01)00491-3

Andreoni, J., \& Petrie, R. (2008). Beauty, gender and stereotypes: Evidence from laboratory experiments. Journal of Economic Psychology, 29(1), 73-93. https:// doi.org/10.1016/j.joep.2007.07.008

Ariely, D. (2008). Predictably irrational. New York: HarperCollins.

Arvey, R.D. (1979). Unfair discrimination in the employment interview: Legal and psychological aspects. Psychological Bulletin, 86(4), 736-765. https://doi. org/10.1037/0033-2909.86.4.736

Benzeval, M., Green, M.J., \& Macintyre, S. (2013). Does perceived physical attractiveness in adolescence predict better socioeconomic position in adulthood? Evidence from 20 years of follow up in a population cohort study. Public Library of Evience, 8(5), e63975. https://doi.org/10.1371/journal.pone.0063975
Scien

Boxall, P., \& Purcell, J. (2008). Strategy and human resource management. New York: Palgrave Macmillan

Caplan, B. (2000). Rational irrationality: A framework for the neoclassical-behaviora debate. Eastern Economic Journal, 26(2), 191-211.

Cash, T.F., Gillen, B., \& Burns, D.S. (1977). Sexism and beautyism in personnel consulting decision making. Journal of Applied Psychology, 62(3), 301-310. https://doi.org/10.1037/0021-9010.62.3.301

Cash, T.F., \& Janda, L.H. (1984). The eye of the beholder. Psychology Today, 18(12), $46-52$
Cash, T.F., \& Kilcullen, R.N. (1985). The Aye of the beholder: Susceptibility to sexism and beautyism in the evaluation of managerial applicants. Journal of Applied Psychology, 15(4), 591-605. https://doi.org/10.1111/j.1559-1816.1985. Applied Psych

Cohen, J. (1988). Statistical power analysis for the behavioral sciences (2nd ed.). New York: New York University.

Davison, H.K., \& Burke, M.J. (2000). Sex discrimination in simulation employment context: A meta-anlytic investigation. Journal of Vocational Behavior, 56(2), 225-248. https://doi.org/10.1006/jvbe.1999.1711

Deaux, K., \& Taynor, J. (1973). Evaluation of male and female ability: Bias works two ways. Psychological Reports, 32(1), 261-262. https://doi.org/10.2466/ pr0.1973.32.1.261

DeGroot, T., \& Gooty, J. (2009). Can nonverbal cues be used to make meaningful personality attributions in employment interviews? Journal of Business and Psychology, 24(2), 179-192. https://doi.org/10.1007/s10869-009-9098-0

Deryugina, T., \& Shurchkov, O. (2015). Now you see it, now you don't: The vanishing beauty premium. Journal of Economic Behavior \& Organization, 11(6), 331-345. https://doi.org/10.1016/j.jebo.2015.05.007

Dion, K.K., \& Stein, S. (1978). Physical attractiveness and interpersonal influence. Journal of Experimental Social Psychology, 14(1), 97-108. https://doi. org/10.1016/0022-1031(78)90063-X

Dipboye, R.L., Arvey, R.D., \& Terpstra, D.E. (1977). Sex and physical attractiveness of raters and applicants as determinants of resume evaluations. Journal of Applied Psychology, 62(3), 288-294. https://doi.org/10.1037/0021-9010.62.3.288

Dipboye, R.L., Fromkin, H.L., \& Wibak, K. (1975). Relative importance of applicant sex, attractiveness and scholastic standing in evaluation of job applicant resumes. Journal of Applied Psychology, 60(1), 39-43. https://doi.org/10.1037/h0076352

Etzioni, A. (2011). Behavioural economics: Next steps. Journal of Consumer Policy, 34(3), 277-287. https://doi.org/10.1007/s10603-011-9160-y

Fletcher, J.M. (2009). Beauty vs. brains: Early labor market outcomes of high schoo graduates. Economics Letters, 105(3), 321-325. https://doi.org/10.1016/j. econlet.2009.09.006

French, M.T. (2002). Physical appearance and earnings: Further evidence. Applied Economics, 34(5), 569-572. https://doi.org/10.1080/00036840010027568

Gerdes, E.P., \& Garber, D.M. (1983). Sex bias in hiring: Effects of job demands and applicant competence. Sex Roles, 9(3), 307-319. https://doi.org/10.1007/ BF00289666

Goldman, W., \& Lewis, P. (1976). Beautiful is good: Evidence that the physically attractive are more socially skillful. Journal of Experimental Social Psychology, 13(2), 125-130. https://doi.org/10.1016/S0022-1031(77)80005-X

Greenhaus, J.H., Parasuraman, S., \& Wormley, W.M. (1990). Effects of race on organizational experiences, job performance evaluations, and career outcomes. Academy of Management Journal, 33(1), 64-88. https://doi.org/10.2307/256352

Hatfield, E. (1986). Mirror, mirror: The importance of looks in everyday life. Albany, NY SUNY Press.

Hamermesh, D.S., \& Biddle, J.E. (1993). Beauty and the labour market. National Bureau of Economic Research, 84(5), 1174-1194.

Heilman, M.E. (1983). Sex bias in work settings: The lack of fit model. Research in Organizational Behavior, 5, 269-298.

Heilman, M.E., \& Saruwatari, L.R. (1979). When beauty is beastly: The effects of appearance and sex on evaluations of job applicants for managerial and nonmanagerial jobs. Organizational Behavior and Human Performance, 23(3), nonmanagerial jobs. Organizational Behavior and Human
360-372. https://doi.org/10.1016/0030-5073(79)90003-5

Holahan, C.K., \& Stephan, C.W. (1981). When beauty isn't talent: The influence of physical attractiveness, attitudes towards women and competence on impression formation. Sex Roles, 7(8), 867-876. https://doi.org/10.1007/BF00287771

Holzer, H. (1993). Multi-city study of urban inequality. Unpublished manuscript, Michigan State University.

Huang, T.C., \& Lin, Y.H. (2016). Self-fulfilling prophecies linking physical attractiveness and interviewer evaluation. Academy of Management Proceedings, 2016(1), 12143. https://doi.org/10.5465/AMBPP.2016.12143abstract

Jin, J., Fan, B., Dai, S., \& Ma, Q. (2017). Beauty premium: Event-related potentials evidence of how physical attractiveness matters in online peer-to-peer lending. Neuroscience Letters, 640,130-135.https://doi.org/10.1016/j.neulet.2017.01.037

Landau, J. (1995). The relationship of race and gender to managers' ratings of promotion potential. Journal of Organizational Behavior, 16(4), 391-400. https:// doi.org/10.1002/job.4030160409

Landy, F.J., \& Farr, J.L. (1980). Performance ratings. Psychological Bulletin, 87(1), 72 107. https://doi.org/10.1037/0033-2909.87.1.72

Langlois, J.H., Kalakanis, L., Rubenstein, A.J., \& Larson, A. (2000). Maxims or myths of beauty? A meta-analytic and theoretical review. Psychological Bulletin, 126(3) 390-423. https://doi.org/10.1037/0033-2909.126.3.390

Ma Q., Qian D., Hu L., \& Wang, L. (2017). Hello handsome! Male's facial attractiveness gives rise to female's fairness bias in Ultimatum Game scenarios - An ERP study. PLoS One, 12(7), e0180459. https://doi.org/10.1371/journal.pone.0180459

Marlowe, C.M., Scheider, S.L., \& Nelson, C.E. (1996). Gender and attractiveness biases in hiring decisions: Are more experienced managers less biased? Journal of Applied Psychology, 81(1), 11-21. https://doi.org/10.1037/0021-9010.81.1.11

Martinko, M.J., \& Gardner, W.L. (1983). A methodological review of sex-related access discrimination problems. Sex Roles, 9(7), 825-839. https://doi.org/10.1007/ BF00290033 
Maurer-Fazio, M., \& Lei, L. (2015). As rare as a panda: How facial attractiveness, gender, and occupation affect interview callbacks at Chinese firms. International
Journal of Manpower, 36(1), 68-85. https://doi.org/10.1108/IJM-12-2014Journal
0258

Mayfield, E.C. (1964). The selection interview: A re-evaluation of published research Personnel Psychology, 17(3), 239-260. https://doi.org/10.1111/j.1744-6570.1964. tb00065.x

McArthur, L.Z., \& Baron, R.M. (1980). Toward an ecological theory of social perception Psychological Review, 90(3), 215. https://doi.org/10.1037/0033-295X.90.3.215

Mobius, M.M., \& Rosenblat, T.S. (2006). Why beauty matters. The American Economic Review, 96(1), 222-235. https://doi.org/10.1257/000282806776157515

Pallant, J. (2010). SPSS survival manual a step by step guide to data analysis using SPSS. (4th edn.). Maidenhead: McGraw Hill.

Patzer, G.L. (1983). Source credibility as a function of communicator physical attractiveness. Journal of Business Research, 11(2), 229-241. https://doi.org/ 10.1016/0148-2963(83)90030-9

Powell, W.W., \& Snellman, K. (2004). The knowledge economy. Annual Review of Sociology, 30, 199-220. https://doi.org/10.1146/annurev.soc.29.010202.100037

Puhl, R., \& Brownell, K.D. (2001). Bias, discrimination, and obesity. Obesity Research, 9(12), 788-805. https://doi.org/10.1038/oby.2001.108

Quereshi, M.Y. (1983). The employability of psychologists in academic settings: A cross-validation. Social Behavior and Personality, 11(1), 17-22. https://doi. org/10.2224/sbp.1983.11.1.17

Quereshi, M.Y., Buckley, J.M., \& Fadden, T.F. (1981). Some determinants of psychologists' employability in academic settings. Personnel Psychology, 34(2), 301-308. https://doi.org/10.1111/j.1744-6570.1981.tb00944.x

Quereshi, M.Y., \& Kay, J.P. (1986). Physical attractiveness, age, and sex as determinants of reactions to resumes. Social Behavior and Personality, 14(1), 103-112. https:// doi.org/10.2224/sbp.1986.14.1.103

Raza, S.M., \& Carpenter, B.N. (1987). A model of hiring decisions in real employment interviews. Journal of Applied Psychology, 72(4), 596-603. https://doi.org/ 10.1037/0021-9010.72.4.596

Ritts, V., Patterson, M.L., \& Tubbs, M.E. (1992). Expectations, impressions and judgements of physically attractive students: A review. Review of Educational Research, 64(4), 413-426. https://doi.org/10.3102/00346543062004413

Robins, P.K., Homer, J.F., \& French, M.T. (2011). Beauty and the labor market: Accounting for the additional effects of personality and grooming. Labour, 25(2) 228-251. https://doi.org/10.1111/j.1467-9914.2010.00511.x

Roehling, M.V. (1999). Weight based discrimination in employment: Psychological and legal aspects. Personnel Psychology, 52, 969-1016. https://doi.org/10.1111/j. 1744-6570.1999.tb00186.x
Roehling, M.V. (2002). Weight discrimination in the American workplace: Ethical issues and analysis. Journal of Business Ethics, 40, 177-189. https://doi.org/ 10.1023/A:1020347305736

Roth, A.E. (1995). Bargaining experiments. In J. Kagel \& E. Roth (Eds.), Handbook of experimental economics, pp. 253-348. Princeton, NJ: Princeton University Press.

Rudolph, C.W., Wells, C.L., Weller, M.D., \& Baltes, B.B. (2009). A meta-analysis of empirical studies of weight-based bias. Journal of Vocational Behavior, 74(1), 1-10. https://doi.org/10.1016/j.jvb.2008.09.008

Ruffle, B.J., \& Shtudiner, Z. (2015). Are good-looking people more employable? Management Science, 61(8), 1760-1776. https://doi.org/10.1287/mnsc.2014. 1927

Rynes, S.L., \& Bourdreau, J.W. (1986). College recruiting in large organizations: Practice, evaluation, and research implications. Personnel Psychology, 39(4), 729757. https://doi.org/10.1111/j.1744-6570.1986.tb00592.x

Saunders, M., Lewis, P., \& Thornhill, A. (2012). Research methods for business students. (6th edn.). Harlow: Pearson Education.

Schmidt, N., \& Lappin, M. (1980). Race and sex as determinants of the mean and variance of performance ratings. Journal of Applied Psychology, 65(4), 428-435. https://doi.org/10.1037/0021-9010.65.4.428

Smith, K.H. (2002). What is the 'knowledge economy'? Knowledge intensity and distributed knowledge bases. Doctoral thesis. Maastricht: Institute for New Technologies, United Nations University.

Solnick, S.J., \& Schweitzer, M.E. (1999). The influence of physical attractiveness and gender on ultimatum game decisions. Organizational Behavior and Human Decision Processes, 79(3), 199-215. https://doi.org/10.1006/obhd.1999.2843

Sutherland, M., \& Jordaan, W. (2004). Factors affecting the retention of knowledge workers. South African Journal of Human Resource Management, 2(2), 55-64. https://doi.org/10.4102/sajhrm.v2i2.39

Sutherland, M., \& Wöcke, A. (2011). The symptoms of and consequences to selection errors in recruitment decisions. South African Journal of Business Management, 42(4), 23-32.

Tews, M.J., Stafford, K., \& Zhu, J. (2009). Beauty revisited: The impact of attractiveness, ability, and personality in the assessment of employment suitability. International
Journal of Selection Assessment, 17(1), 92-100. https://doi.org/10.1111/j.1468Journal of Selection

Tomer, J.F. (2007). What is behavioral economics? The Journal of Socio-Economics, 36(3), 463-479. https://doi.org/10.1016/j.socec.2006.12.007

Watkins, L.M., \& Johnston, L. (2000). Screening job applicants: The impact of physical attractiveness and application quality. International Journal of Selection and Assessment, 8(2), 76-84. https://doi.org/10.1111/1468-2389.00135

Yamamura, L.M., \& Birk, C.A. (2010). Attracting and retaining talent: The importance of first impressions. CPA Journal, 80(4), 58-60. 